\title{
PENGARUH SERVANT LEADERSHIP DAN KOMITMEN ORGANISASIONAL TERHADAP KINERJA KARYAWAN BAGIAN DANA BANK SULTRA KENDARI
}

\author{
Marsitha Zubha Sakinah Basalama ${ }^{1}$ \\ Putu Saroyini Piartrini²
}

${ }^{1,2}$ Fakultas Ekonomi dan Bisnis Universitas Udayana (Unud), Bali, Indonesia email: mrsthzsb@gmail.com

\begin{abstract}
ABSTRAK
Tujuan penelitian ini adalah untuk mengetahui pengaruh servant leadership dan komitmen organisasional terhadap kinerja karyawan. Penelitian dilakukan di Bank Sultra Kendari. Penelitian ini menggunakan seluruh populasi sebanyak 50 responden Bagian Dana dan data yang digunakan berupa kuesioner. Teknik analisis data menggunakan analisis regresi linear berganda. Berdasarkan hasil pengujian didapatkan hasil servant leadership berpengaruh positif dan signifikan terhadap kinerja karyawan, dibuktikan dengan koefisien beta sebesar ( $\beta$ ) 0,342 dengan nilai signifikan 0,004 . Komitmen organisasional berpengaruh positif dan signifikan terhadap kinerja karyawan, dibuktikan dengan koefisien beta sebesar ( $\beta$ ) 0,651 dengan nilai signifikan 0,001 . Nilai koefisien determinasi $\left(\mathrm{R}^{2}\right)$ sebesar 0,836 atau 83,6 persen kinerja karyawan Bank Sultra Kendari dipengaruhi oleh servant leadership dan komitmen organisasional, sedangkan sisanya sebesar 16,4 persen dipengaruhi oleh variable lain.
\end{abstract}

Kata Kunci: servant leadership, komitmen organisasional, kinerja karyawan

\begin{abstract}
The purpose of this study was to determine the effect of servant leadership and organizational commitment on employee performance. The research was conducted at Kendari Southeast Sulawesi Bank. This study uses a whole population of 50 respondents in the Fund Section and the data used in the form of a questionnaire. The technique of data analysis uses double linear regression analysis. Based on the test results obtained the results of servant leadership have a positive and significant effect on employee performance, as evidenced by the beta coefficient of ( $\beta$ ) 0.342 with a significant value of 0.004 . Organizational commitment has a positive and significant effect on employee performance, as evidenced by the beta coefficient of ( $\beta) 0.651$ with a significant value of 0.001 . The coefficient of determination (R2) of 0.836 or 83.6 percent of the performance of Southeast Sulawesi Bank employees is influenced by servant leadership and organizational commitment, while the remaining 16.4 percent is influenced by other variables.
\end{abstract}

Keywords: servant leadership, organizational commitment, employee performance 


\section{PENDAHULUAN}

Bank Pembangunan Daerah (BPD) yang kini berubah menjadi Bank Sultra merupakan salah satu badan usaha milik daerah (BUMD) yang bergerak dibidang jasa keuangan. Saat ini persaingan bisnis antar lembaga perbankan yang ada di Kota Kendari semakin ketat. Hal ini sudah tentu menuntut proses pendewasaan dari perbankan Indonesia ke arah profesionalisme dan komplektisitas yang tinggi dapat menimbulkan resiko yang akan di hadapi oleh bank-bank yang ada di Indonesia (Fauzan dan Sumiyati, 2014). Sukses atau tidaknya kegiatan yang dijalankan oleh suatu perusahan tergantung pada kemampuan yang dimiliki oleh sumber daya manusia dalam perusahaan itu sendiri (Adi et al., 2016) .maka dibutuhkan kinerja sumber daya manusia atau karyawan yang ada agar apa yang menjadi tujuan organisasi dapat tercapai yakni berupa laba atau keuntungan yang optimal.

Sumberdaya manusia merupakan faktor terpenting dalam menggerakkan jalannya roda organisasi apapun. Oleh karena itu, sumber daya manusia harus senantiasa dijaga dan dikelola dengan baik sehingga mampu berkinerja baik dalam rangka mendukung pencapaian tujuan yang telah ditetapkan. Banyak fakta membuktikan bahwa organisasi yang berkembang dengan pesat dan besar selain ditopang dengan financial organisasi yang baik, juga didukung oleh sumberdaya manusia yang baik pula.

Menghadapi dinamika industri jasa perbankan Bank Sultra sebagai bank milik pemerintah daerah terus melakukan pembenahan dalam rangka menghadirkan layanan perbankan bagi masyarakat Sultra. Guna mendukung pertumbuhan dana, di tahun 2017 Bank Sultra membuka operasional Kantor Kas Rante Angin di Kec.Rante Angin, Kab. Kolaka Utara serta menambah mesin ATM dibeberapa lokasi strategis. Sehingga ditahun 2017 jaringan kantor Bank Sultra mencapai 72 (tujuh puluh dua) kantor serta 60 (enam puluh) unit ATM.

Jika dilihat dari lima tahun terakhir trend positif penerimaan laba bersih setelah pajak terus menunjukan peningkatan, dimana pada tahun 2012 laba hanya mencapai Rp110 miliar, kemudian tahun 2014 naik menjadi Rp117 miliar dan terakhir 2017 mencapai angka Rp185 miliar. Pencapaian ini tidakterlepas dari upaya manajemen dan karyawan dalam menjaga kualitas aktiva produktif. Terbukti dengan membaiknya Non Performing Loan (NPL) gross dari 2,30\% tahun 2016 menjadi diposisi 1,82\% tahun 2017. Berdasarkan keterangan diatas dikatakan adanya pertumbuhan kinerja Bank Sultra yang cenderung mengalami kenaikan dari tahun ke tahun, yang di sebabkan oleh kinerja karyawan yang baik. Kinerja adalah melakukan pekerjaan secara lebih giat sehingga pekerjaan dapat diharapkan lebih cepat dan lebih baik (Suryadharma et al., 2016).

Banyak faktor yang diduga dapat mempengaruhi kinerja karyawan, salah satunya adalah kepemimpinan. Peranan seorang pemimpin sangat penting dalam sebuah organisasi. Oleh sebab itu, kemajuan sebuah organisasi juga tergantung dari figur kepemimpinan yang tercermin melalui sifat, metode dan gaya kepemimpinannya. Seorang pemimpin yang dapat membawa dan mengarahkan para bawahanya untuk bekerja dengan lebih baik adalah pemimpin yang tentunya disenangi sekaligus disegani oleh bawahanya. 
Studi awal penulis melakukan wawancara kepada karyawan kepala bagian yang bernama Fauzi Jibran, beliau mengungkapkan bahwa "pimpinan pada Bank Sultra selama ini lahir dari dalam organisasi itu sendiri, karena pola kepemimpinan manajemen yang berasal dari dalam organisasi cenderung menunjukan karakteristik servant leadership, salah satu contohnya pimpinan turun langsung ke divisi hingga staff terbawah untuk memberitahukan target kerja yang harus dicapai, dimana atasan memberi informasi yang saya butuhkan untuk melakukan pekerjaan saya dengan baik". Wawancara selanjutnya kepada karyawan Nuryanti yang mengungkapkan bahwa "atasan mengakui kesalahannya kepada kami (karyawan) dan tidak segan meminta maaf ketika beliau melakukan kesalahan". Taufik mengatakan "atasan saya memuji ketika target tercapai dan ketika target tidak tercapai, atasan tidak langsung memarahi tetapi memberikan masukan dan semangat agar saya lebih baik lagi dalam bekerja.”. Berdasarkan hasil wawancara kepada 3 karyawan Dana di Bank Sultra menunjukkan adanya kepemimpinan melayani (servant leadership), dimana pemimpin yang sangat peduli atas pertumbuhan dan dinamika kehidupan pengikut, dirinya serta komunitasnya, karena itu ia mendahulukan hal-hal tersebut daripada pencapaian ambisi pribadi dan kesukaan semata (Vondey, 2008). Karyawan yang mempunyai keterlibatan tinggi dalam bekerja dan tidak mempunyai keinginan keluar dari perusahaan, maka hal ini merupakan modal dasar untuk mendorong produktifitas yang tinggi. Komitmen (Dramawan, 2017)

Salah satu gaya kepemimpinan yang diterapkan di Bank Sultra adalah gaya kepemimpinan servant leadership. Teori kepemimpinan melayani merupakan salah satu gaya ideal dalam menciptakan sumber daya manusia. Gaya kepemimpinan ini sangat cocok diterapkan oleh perusahaan karena berfokus pada kontribusi terhadap pembangunan daerah yang mengedepankan pelayanan baik untuk mencapai misi dan visi perusahaan (Mazarei et al., 2013). Gaya kepemimipnan ini merupakan faktor yang sangat menunjang untuk peningkatan kinerja karyawan, dimana pemimpin mau mendengarkan dan menerima kritikan dari karyawan dan tidak memandang jabatan serta pemimpin turun langsung untuk memberikan pengarahan sehingga membuat karyawan merasa nyaman dalam meningkatkan diri, khususnya di bagian Dana. Hasil penelitian Purwandari (2016) menunjukan bahwa servant leadership berpengaruh positif dan signifikan terhadap kinerja karyawan .

Kemampuan memahami karakteristik dan kultur organisasi ini juga mendorong kuatnya komitmen organisasi pegawai-pegawai yang menjadi bawahannya dimana intensi turnover pegawai Bank Sultra selama lima tahun terakhir rata-rata hanya berkisar $1,68 \%$ jauh dari rata-rata intensi turnover karyawan bank secara nasional sebesar $15 \%$. Ini karena gaya manajemen dapat mempengaruhi tingkat komitmen karyawan.

Studi selanjutnya dilakukan dengan mewawancarai 5 orang karyawan bagian Dana di Bank Sultra yaitu Ulfa, Nur, Sianturi, Noviantika dan Rizky (nama asli disamarkan). Pendapat Ulfa "saya merasa nyaman dan berkeinginan menghabiskan karir di organisasi ini, karena sudah seperti keluarga sendiri”. Menurut pendapat Nur "saya senang dengan pekerjaan ini karena pegawainya bisa bekerja dalam tim. Sianturi mengatakan "saya sudah merasa cukup senang dan 
nyaman ditempat saya bekerja dan tidak memiliki keinginan untuk keluar dari organisasi ini". Noviantika mengatakan "saya memulai karir di Bank Sultra dari bawah sekali sehingga ketika saya menaiki jabatan dan bisa sampai di posisi ini saya berjanji untuk tetap di kantor Bank Sultra" dan yang terakhir. Rizky mengatakan "kalau saya meninggalkan perusahaan ini, kemungkinan untuk mendapatkan kenyamanan dan fasilitias yang sekarang saya dapat belum tentu saya mendapatkannya di perusahaan lain”. Berdasarkan hasil wawancara kepada kelima karyawan dibagian Dana maka ditemukan karyawan memiliki komitmen organisasional yang kuat. Komitmen organisasional adalah tingkat kepercayaan seseorang dan penerimaan tenaga kerja terhadap tujuan organisasi dan memiliki keinginan untuk tetap bertahan dalam organisasi ini (Mathis \& Jackson, 2001).

Berdasarkan latar belakang dan fenomena diatas maka penulis berusaha untuk mengeksplorasi peran kepemimpinan melayani di Bank Sultra. Penelitian ini mengembangkan kerangka konseptual yang mencoba menjelaskan hubungan antara kepemimpinan melayani dan komitmen organisasional terhadap kinerja karyawan. Adapun alasan pemilihan topik seperti yang sudah dijabarkan diatas yaitu adanya pertumbuhan kinerja Bank Sultra dikarenakan kinerja karyawan yang baik yang diduga dipengaruhi oleh gaya kepemimpinan melayani (servant leadership) dan komitmen organisasional, maka alasan tersebut mendasari penelitian ini mengambil judul "Pengaruh Servant Leadership dan Komitmen Organisasional Terhadap Kinerja Karyawan (Studi Pada Kantor Bank Sultra)”.

Kinerja organisasi sangat ditentukan oleh unsur pegawainya, karena itu mengukur kinerja suatu organisasi sebaiknya diukur dalam tampilan kerja dari pegawainya. Menurut Wirawan (2009) kinerja adalah keluaran yang dihasilkan oleh fungsi-fungsi atau indikator-indikator suatu pekerjaan atau suatu profesi dalam waktu tertentu. Kinerja adalah hasil kerja yang dilakukan oleh seseorang atau organisasi yang bersangkutan. Kinerja yang lebih tinggi mengandung arti terjadinya peningkatan efisiensi, efektivitas, atau kualitas yang lebih tinggi dari penyelesaian serangkaian tugas yang dibebankan kepada seorang karyawan dalam suatu organisasi atau perusahaan (Murty et al., 2012). Proses penilaian dilakukan dengan membandingkan kinerja pegawai terhadap standar yang telah ditetapkan atau memperbandingkan kinerja antar pegawai yang memiliki kesamaan tugas.

Dalam menilai kinerja karyawan Bank Sultra menggunakan Balance Scorecard. Balance Scorecard menurut Kaplan dan Norton (1992) terdiri dari 4 indikator yaitu : (1) perspektif keuangan (2) perspektif pelanggan (3) perspektif bisnis (4) perspektif pembelajaran dan pertumbuhan.

Servant Leadership merupakan salah satu model pendekatan kepemimpinan dengan memposisikan diri sebagai pelayan dengan mengutamakan orang lain ketimbang dirinya sendiri (Sen \& Sarros, 2002). Menurut Trompenaars dan Voerman (2010) servant leadership adalah gaya manajemen dalam hal memimpin dan melayani berada dalam satu harmoni dan terdapat interaksi dengan lingkungan. Pemimpin yang melayani adalah seorang pemimpin yang mengutamakan pelayanan, dimulai dengan perasaan alami seseorang yang ingin melayani dan untuk mendahulukan pelayanan (Spears, 2010). Selanjutnya secara sadar, pilihan ini membawa aspirasi dan dorongan dalam memimpin orang lain. 
Setidaknya ada dua alasan mengapa kepemimpinan pelayan meningkatkan potensi tim dan efektivitas tim berikutnya. Pertama, para pemimpin bertindak demi kepentingan terbaik bawahan mereka (Walumbwa et al.,2010) Pemimpin pelayan mendapatkan kepercayaan anggota tim dan membangun hubungan jangka panjang dengan menunjukkan perhatian yang tulus untuk semua anggota tim (Liden et al., 2014). Selanjutnya, menurut Van Dierendonck dan Nuijten (2011) bahwa ada 7 dimensi untuk mengukur servant leadership yaitu: (1) standing back (2) courage (3) empowerment (4) accountability (5) humility (6) interpersonal acceptance (7) stewardship.

Menurut Allen dan Meyer (1990) mendefinisikan komitmen organisasional adalah orang-orang yang mengenal organisasi dan terikat untuk tetap menjadi anggota organisasi untuk mencapai tujuan organisasi, mereka menganggap bahwa mereka tetap tinggal dalam organisasi tersebut karena mereka akan mendapatkan uang pensiun, fasilitas dan senioritas ketimbang mereka harus mengeluarkan biaya karena pindah kerja. Sementara Mowday et al. (1982) mengatakan bahwa komitmen adalah kuatnya pengenalan dan keterlibatan seseorang dalam suatu organisasi tertentu.

Pegawai bertahan menjadi anggota organisasi karena ada kesadaran bahwa berkomitmen terhadap organisasi merupakan hal yang memang seharusnya dilakukan. Indikator pengukuran komitmen organisasional menurut Allen dan Meyer (1990) adalah sebagai berikut: (1) komitmen affektif (2) komitmen berkelanjutan (3) komitmen normatif.

Path Goal Theory suatu model kepemimpinan yang dikembangkan oleh Robert J. House dimana pemimpin membantu karyawan terhadap sasaransasasran kerja dan meminimalisirkan hambatan kinerja, pemimpin melakukannya dengan memberikan arahan, dukungan dan informasi yang dibutuhkan oleh karyawan. Path Goal Theory menganut pandangan kemempinan sebagai pelayan ini sesuai dengan karakteristik servant leadership yaitu stewardship dimana pemimpin bertindak sebagai panutan. Penerapan sevant leadership dalam oganisasi pada dasarnya untuk meningkatkan kinerja bawahan atau karyawan, hal tersebut sesuai dengan hasil penelitian yang dilakukan oleh Indartono et al. (2010) ditunjukkan bahwa adanya hubungan positif dan signifikan antara servant leadership style terhadap kinerja karyawan. Kemudian penelitian selanjutnya diungkapkan bahwa Sial et al. (2014) melakukan penelitian dengan didapatkan hasil gaya kepemimpinan yang melayani (servant leadership) baik secara langsung maupaun tidak langsung melalui perantara variabel seperti sikap, norma subyektif dan pengendalian perilaku dapat mempengaruhi berbagai pengetahuan serta kehebatan pada karyawan di perguruan tinggi. Kemudian penelitian yang dilakukan juga oleh Harianto et al. (2014) menyimpulkan hasil penelitian yang mengatakan bahwa servant leadership Kepala Dinas berpengaruh berpengaruh positif dan signifikan terhadap Kinerja pegawai di Dinas PU Pengairan Kabupaten Banyuwangi. Hal ini juga didukung oleh Penelitian yang dilakukan oleh Purwandari (2016) menemukan bahwa servant leadership berpengaruh positif dan signifikan terhadap kinerja karyawan Child Development Sponsor Program Compassion Indonesia Cluster DIY. Serta penelitian yang dilakukan oleh Muhammad Aji (2016) mengatakan bahwa adanya servant leardeship 
berpengaruh positif dan signifikan terhadap kinerja karyawan. Berdasarkan hasil penelitian tersebut dapat dirumuskan hipotesis sebagai berikut:

$\mathrm{H}_{1}$ : Servant leadership berpengaruh signifikan terhadap kinerja karyawan pada Bank Sultra.

Menurut Blau (1964) dalam Teori Pertukaran Social (social exchange theory) menunjukkan bahwa karyawan akan termotivasi dan komitmen pada pekerjaan di organisasi apabila diperlakukan dengan adil dan seimbang. Lebih lanjut Muhammad dan Abdullah (2016) menjelaskan tentang hubungan timbal balik karyawan dengan organisasi, organisasi yang memberikan karyawan dukungan dan mengakui pandangan karyawan dalam pengambilan kuputusan, karyawan akan membalas dengan komitmen terhadap organisasi. SET menjadi dasar bagaimana pemimpin dalam perusahaan memahami prilaku kerja karyawannya, ini akan mengimplikasikan bahwa karyawan diperlakukan dengan baik oleh perusahaan sehingga karyawan memiliki komitmen untuk memberikan balasan dengan perilaku positif melalui kinerja karyawan. Dimana komitmen bisa dianggap sebagai bentuk timbal balik karyawan terhadap apa yang mereka terima dari organisasi. Penelitian yang telah dilakukan oleh (Syauta et al., 2010) yang menguji hubungan antara variabel dengan menggunakan analisis inferensial dengan Partial Least Square (PLS) metode dan Sobel Test didapatkan hasil penelitian yaitu komitmen organisasional berpengaruh secara signifikan terhadap kinerja karyawan secara langsung atau tidak langsung melalui kepuasan kerja.Karyawan yang memiliki komitmen organisasional yang tinggi akan cenderung melakukan hal yang terbaik untuk organisasi tempat ia bekerja sehingga akan menunjukkan performa kerja (kinerja) yang baik pula. Selanjutnya Irefin dan Mechanic (2014) menemukan bahwa ada hubungan yang cukup tinggi antara komitmen karyawan dengan kinerja organisasi pada Coca Cola Nigeria Limited Maiduguri, Borno State. Kemudian hasil temuan empiris yang dilakukan oleh Arina (2014) menunjukan bahwa komitmen organisasional berpengaruh positif dan signifikan terhadap kinerja karyawan. Selanjutnya Lotunani et al, (2014) mengungkapkan bahwa komitmen berpengaruh positif dan signifikan terhadap kinerja pegawai negeri. Hal ini juga di pertegas dengan hasil penelitian oleh Kamanjaya \& Supartha (2017) menunjukkan bahwa komitmen organisasional pegawai berpengaruh positif dan signifikan terhadap kinerja pegawai. Artinya, bahwa jika komitmen organisasional pegawai meningkat, maka kinerja pegawai RSUD Wangaya Kota Denpasar juga akan meningkat. Berdasarkan hasil penelitian tersebut dapat dirumuskan hipotesis sebagai berikut :

$\mathrm{H}_{2}$ : Komitmen organisasional berpengaruh signifikan terhadap kinerja karyawan pada Bank Sultra.

\section{METODE PENELITIAN}

Lokasi penelitian ini dilaksanakan di kantor pusat dan Cabang Pembantu Bank Sultra Kendari yang terletak di Jalan Mayjend Soetoyo No.95 Kendari Sulawesi Tenggara (Kantor Pusat) dan di Jalan Sao-Sao No 272 Kendari Sulawesi Tenggara (Cabang Pembantu). Lokasi ini dipilih karena kinerja karyawan yang ada di Bank Sultra dari tahun ke tahun mengalami peningkatan yang baik 
sehingga penulis ingin menguji hubungan antara kepemimpinan melayani dan komitmen organisasional terhadap kinerja karyawan.

Adapun model regresi linear berganda yang dijabarkan dengan menggunakan persamaan sebagai berikut:

Dimana :

$$
\mathrm{Y}=\mathrm{a}+\beta_{1} \mathrm{X}_{1}+\beta_{2} \mathrm{X}_{2}+\mathrm{e}
$$

$\mathrm{Y}=$ Kinerja karyawan

$\mathrm{X}_{1}=$ Servant leadership

$\mathrm{X}_{2}=$ Komitmen organisasional

$\mathrm{a}=$ Konstanta regresi berganda.

$\beta 1, \beta 2=$ Koefisien regresi

$\mathrm{e}=\operatorname{error}$ (variabel bebas lain diluar model regresi).

\section{HASIL DAN PEMBAHASAN}

\section{Tabel 1.}

Karakteristik Responden Bank Sultra Kendari

\begin{tabular}{|c|c|c|c|c|}
\hline No & Variabel & Klasifikasi & Jumlah (Orang) & Presentase $(\%)$ \\
\hline \multirow{3}{*}{1} & \multirow{2}{*}{ Jenis Kelamin } & Perempuan & 19 & 38 \\
\hline & & \multirow[t]{2}{*}{ Laki-laki } & 31 & 62 \\
\hline & \multirow{4}{*}{ Usia (Tahun) } & & 50 & 100 \\
\hline \multirow{4}{*}{2} & & $20-30$ & 18 & 36 \\
\hline & & $31-40$ & 22 & 44 \\
\hline & & $41-50$ & 10 & 20 \\
\hline & \multicolumn{2}{|c|}{ Jumlah } & 50 & 100 \\
\hline \multirow{4}{*}{3} & \multirow{3}{*}{ Pendidikan } & SLTA & 35 & 70 \\
\hline & & Diploma (D3) & 2 & 4 \\
\hline & & Sarjana (S1) & 13 & 26 \\
\hline & \multirow{5}{*}{ Masa Kerja } & & 50 & 100 \\
\hline \multirow{4}{*}{4} & & $\leq 1-5$ & 10 & 20 \\
\hline & & $6-10$ & 34 & 68 \\
\hline & & $\geq 11$ & 6 & 12 \\
\hline & & & 50 & 100 \\
\hline
\end{tabular}

Sumber : Data diolah, 2018

Berdasarkan pada Tabel 1. responden di bagian Dana pada penelitian di Bank Sultra Kendari dominan berjenis kelamin laki-laki berjumlah 31 orang dengan presentase 62 persen, Dilihat dari segi usia, responden sebagian besar berusia 31 sampai 40 tahun dengan presentase 44 persen dan sebagian besar Pendidikan terakhir responden dominan SLTA yaitu sebanyak 35 orang dengan presentase 70 persen. Dilihat dari Pendidikan terakhir seperti yang sudah di jelaskan oleh Bapak Fauzi Jibran menunjukkan bahwa para atasan lebih memprioritaskan karyawan dari dalam perusahaan daripada mengrekrut karyawan dari luar perusahaan serta masa kerja paling banyak adalah 6-10 tahun yakni 34 orang dengan persentase sebesar 68 persen. Dilihat dari masa kerja menunjukkan bahwa pegawai memiliki komitmen organisasional yang cukup baik bekerja di Bank Sultra Kendari dengan masa kerja sampai 10 tahun. 
Menurut Hair et al. (1998) Instrumen dikatakan valid jika bernilai factor loading item $>0.4$, dengan nilai Keiser Olkin Meyer 0.50, Commulative Explained Variance $>0,50$ atau $50 \%$ dan nilai Eigen factor $>1.0$.

Hasil uji validitas dan reliabilitas data variabel servant leadership disajikan pada Tabel 2, variabel komitmen organisasional disajikan pada Tabel 3, dan variabel kinerja karyawan disajikan pada Tabel 4.

Tabel 2.

Uji Validitas Dan Reliabilitas Variabel Servant Leadership

\begin{tabular}{ccccccc}
\hline Faktor & Indikator & $\begin{array}{c}\text { Factor } \\
\text { loading }\end{array}$ & $\begin{array}{c}\text { Eigen } \\
\text { value } \\
\text { faktor }\end{array}$ & KMO & $\begin{array}{c}\text { Variance } \\
\text { Explained } \\
\text { (\%) }\end{array}$ & $\begin{array}{c}\text { Realibilitas } \\
\text { Cronvach's } \\
\text { Alpha }\end{array}$ \\
\hline \multirow{4}{*}{ F.1 } & $\mathrm{X}_{1.1}$ & 0,934 & 3.295 & 0,538 & 79.478 & 0.709 \\
& $\mathrm{X}_{1.4}$ & 0,825 & & & & \\
& $\mathrm{X}_{1.5}$ & 0,593 & & & & \\
F.2 & $\mathrm{X}_{1.9}$ & 0,882 & & & & \\
& $\mathrm{X}_{1.8}$ & 0,957 & 2.110 & & & \\
F.3 & $\mathrm{X}_{1.10}$ & 0,963 & & & & \\
& $\mathrm{X}_{1.2}$ & 0,697 & 1.431 & & & \\
F.4 & $\mathrm{X}_{1.7}$ & 0,731 & & & & \\
\hline
\end{tabular}

Sumber : Data diolah, 2018

Model faktor mencerminkan dimensi konstruk yang dinilai layak. Hasil analisis yang menunjukkan jumlah data sampel memadai dengan ditunjukkannya nilai Kaiser Meyer Olkin Measure of Sampling Adequacy $(\mathrm{KMO})=0.538$. Indikator dikelompokkan menjadi empat faktor berdasarkan nilai eigen value $>1$ keseluruhan faktor mampu menjelaskan variance total 79.478 , maka servant leadership dinilai memiliki validitas memadai. Data variabel servant leadership memiliki parameter Alpha Cronbach $=0.709$, sehingga pernyataan pada kuesioner tersebut dinyatakan reliabel.

Tabel 3.

Uji Validitas Dan Reliabilitas Variabel Komitmen Organisasional

\begin{tabular}{ccccccc}
\hline Faktor & Indikator & $\begin{array}{c}\text { Factor } \\
\text { loading }\end{array}$ & $\begin{array}{c}\text { Eigen } \\
\text { value } \\
\text { faktor }\end{array}$ & KMO & $\begin{array}{c}\text { Variance } \\
\text { Explained } \\
\text { (\%) }\end{array}$ & $\begin{array}{c}\text { Realibilitas } \\
\text { Cronvach's } \\
\text { Alpha }\end{array}$ \\
\hline F.1 & $\mathrm{X}_{2.1}$ & 0.787 & 3.099 & 0.569 & 78.425 & 0.689 \\
& $\mathrm{X}_{2.4}$ & 0.840 & & & & \\
& $\mathrm{X}_{2.5}$ & 0.482 & & & & \\
F.2 & $\mathrm{X}_{2.9}$ & 0.877 & & & & \\
& $\mathrm{X}_{2.7}$ & 0.936 & 2.011 & & & \\
F.3 & $\mathrm{X}_{2.8}$ & 0,938 & & & & \\
& $\mathrm{X}_{2.2}$ & 0.740 & 1.615 & & & \\
F.4 & $\mathrm{X}_{2.10}$ & 0.688 & & & & \\
& $\mathrm{X}_{2.3}$ & 0.833 & 1.118 & & & \\
\hline
\end{tabular}

Sumber : Data diolah, 2018 
Model faktor mencerminkan dimensi konstruk yang dinilai layak. Hasil analisis yang menunjukkan jumlah data sampel memadai dengan ditunjukkannya nilai Kaiser Meyer Olkin Measure of Sampling Adequacy (KMO) $=0.569$. Indikator dikelompokkan menjadi empat faktor berdasarkan nilai eigen value $>1$ keseluruhan faktor mampu menjelaskan variance total 78.425 , maka komitmen organisasional dinilai memiliki validitas memadai. Data variabel servant leadership memiliki parameter Alpha Cronbach $=0.689$, sehingga pernyataan pada kuesioner tersebut dinyatakan reliabel.

Tabel 4.

Uji Validitas Dan Reliabilitas Variabel Kinerja Karyawan

\begin{tabular}{ccccccc}
\hline Faktor & Indikator & $\begin{array}{c}\text { Factor } \\
\text { loading }\end{array}$ & $\begin{array}{c}\text { Eigen } \\
\text { value } \\
\text { faktor }\end{array}$ & KMO & $\begin{array}{c}\text { Variance } \\
\text { Explained } \\
\text { (\%) }\end{array}$ & $\begin{array}{c}\text { Realibilitas } \\
\text { Cronvach's } \\
\text { Alpha }\end{array}$ \\
\hline F.1 & $\mathrm{Y}_{1}$ & 0.678 & 2.914 & 0.579 & 76.981 & 0.696 \\
& $\mathrm{Y}_{2}$ & 0.625 & & & & \\
& $\mathrm{Y}_{4}$ & 0.415 & & & & \\
& $\mathrm{Y}_{5}$ & 0.704 & & & & \\
& $\mathrm{Y}_{7}$ & 0.669 & & & & \\
F.2 & $\mathrm{Y}_{9}$ & 0,611 & & & & \\
& $\mathrm{Y}_{3}$ & 0.792 & 2.010 & & & \\
& $\mathrm{Y}_{6}$ & 0.779 & & & & \\
$\mathrm{~F} .4$ & $\mathrm{Y}_{10}$ & 0.555 & & & & \\
\hline
\end{tabular}

Sumber : Data diolah, 2018

Model faktor mencerminkan dimensi konstruk yang dinilai layak. Hasil analisis yang menunjukkan jumlah data sampel memadai dengan ditunjukkannya nilai Kaiser Meyer Olkin Measure of Sampling Adequacy (KMO) $=0.579$. Indikator dikelompokkan menjadi empat faktor berdasarkan nilai eigen value $>1$ keseluruhan faktor mampu menjelaskan variance total 76.981, maka servant leadership dinilai memiliki validitas memadai. Data variabel kinerja karyawan memiliki parameter Alpha Cronbach $=0.696$, sehingga pernyataan pada kuesioner tersebut dinyatakan reliabel.

Tabel 5.

Hasil Analisis Regresi Linear Berganda

\begin{tabular}{|c|c|c|c|c|c|c|c|}
\hline \multirow{3}{*}{ Model } & \multicolumn{5}{|c|}{ Coefficients $^{a}$} & \multirow{2}{*}{\multicolumn{2}{|c|}{$\begin{array}{c}\text { Collinearity } \\
\text { Statistics }\end{array}$}} \\
\hline & \multicolumn{2}{|c|}{$\begin{array}{l}\text { Unstandardized } \\
\text { Coefficients }\end{array}$} & \multirow{2}{*}{$\begin{array}{c}\text { Standardized } \\
\text { Coefficients } \\
\text { Beta }\end{array}$} & \multirow{2}{*}{$\mathbf{T}$} & \multirow{2}{*}{ Sig. } & & \\
\hline & B & $\begin{array}{l}\text { Std. } \\
\text { Error }\end{array}$ & & & & Tolerance & VIF \\
\hline (Constant) & .645 & 4.558 & & .142 & .888 & & \\
\hline $\begin{array}{l}\text { Servant } \\
\text { Leadership }\end{array}$ & .342 & .113 & .421 & 3.028 & .004 & .181 & 5.533 \\
\hline $\begin{array}{l}\text { Komitmen } \\
\text { Organisasional }\end{array}$ & .651 & .175 & .516 & 3.715 & .001 & .181 & 5.533 \\
\hline
\end{tabular}

Sumber: Data diolah, 2018 
Berdasarkan Tabel 5. yang menyajikan hasil dari analisis regresi berganda, maka persamaan regresi yang digunakan dalam penelitian ini dapat ditulis sebagai berikut:

$$
\mathrm{Y}=0,645+0,342 \mathrm{X}_{1}+0,651 \mathrm{X}_{2}
$$

Hubungan antara variabel servant leadership dan komitmen organisasional terhadap kinerja karyawan di Bank Sultra. Persamaan regresi linear berganda tersebut dapat dijelaskan sebagai berikut :

$\mathrm{X}_{1}=\quad+0,342$, yang menunjukkan bahwa Servant Leadership $\left(\mathrm{X}_{1}\right)$ berpengaruh positif terhadap Kinerja Karyawan (Y) di Bank Sultra.

$\mathrm{X}_{2}=+0,651$, yang menunjukkan bahwa Komitmen Organisasional $\left(\mathrm{X}_{2}\right)$ berpengaruh positif terhadap Kinerja Karyawan (Y) di Bank Sultra.

Uji normalitas bertujuan untuk menguji apakah satu asumsi dasar analisis regresi berganda yaitu variabel - variabel independen dan dependen harus berdistribusi normal atau mendekati normal. Untuk menguji apakah data yang dikumpulkan berdistribusi normal atau tidak dalam penelitian ini diuji dengan menggunakan uji Kolmogorov-Smirnov dengan nilai probabilitas Asymp-Sig (2tailed) $>0,05$ maka butir item pertanyaan tersebut berdistribusi normal. Hasil uji normalitas selanjutnya dapat dilihat pada tabel sebagai berikut:

Tabel 6.

Uji Asumsi Normalitas

\begin{tabular}{lr}
\hline & Unstandardized Residual \\
\hline $\mathrm{N}$ & 50 \\
Test Statistic & .084 \\
Asymp. Sig. (2-tailed) & $.200^{\mathrm{c}, \mathrm{d}}$ \\
\hline Sumber: Data diolah, 2018
\end{tabular}
Sumber: Data diolah, 2018

Uji multikolinearitas dilakukan untuk menguji apakah pada model regresi ditemukan adanya kolerasi antar variabel independen (bebas) atau tidak. Jika terjadi korelasi maka dapat dikatakan terkena gejala multikolinearitas. Untuk menguji ada tidaknya gejala multikolinearitas dilakukan dengan uji VIF (Variance Inflantion Factor) dan tolerance. Jika perhitungan nilai VIF di bawah 10 dan tolerance variabel bebas di atas 10 maka dapat disimpulkan bahwa model regresi tersebut tidak terjadi multikolinearitas. Hasil uji multikolinearitas selanjutnya dapat dilihat pada tabel sebagai berikut:

Tabel 7.

Uji Asumsi Multikolinearitas

\begin{tabular}{lcc}
\hline \multicolumn{1}{c}{ Model } & \multicolumn{2}{c}{ Collinearity Statistics } \\
Tolerance & VIF \\
\hline Servant Leadership & .181 & 5.533 \\
Komitmen Operasional & .181 & 5.533 \\
\hline
\end{tabular}

Sumber: Data diolah, 2018 
Uji heteroskedastisitas dalam penelitian ini menggunakan scatterplot pada uji regresi yang telah dilakukan sebelumnya. Yang perlu diperhatikan dalam pengujian ini adalah dengan melihat ada tidaknya pola tertentu pada scatterplot dari variabel terikat dimana jika tidak terbentuk pola tertentu maka tidak terjadi heteroskedatisitas namun apabila terdapat pola tertentu maka terjadi heteroskedastisitas pada data yang digunakan pada penelitian. Hasil uji heterokedastisitas selanjutnya dapat dilihat pada gambar berikut:

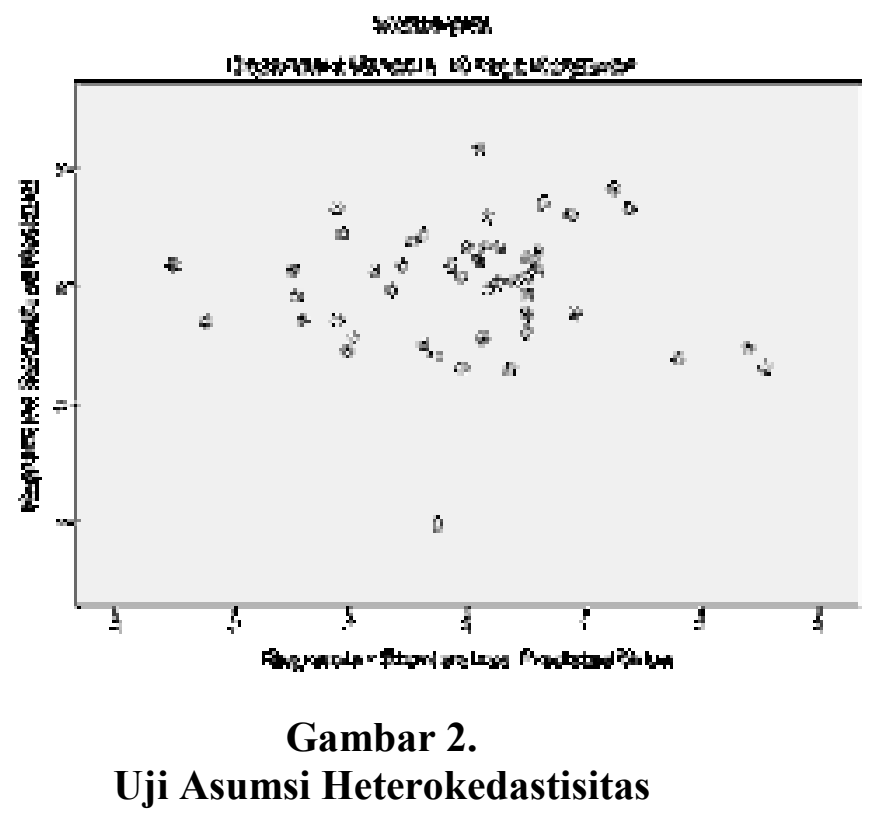

Sumber: Data diolah, 2018

Berdasarkan hasil uji, nilai signifikan $\mathrm{F}$ adalah sebesar 0,000 yang lebih kecil dari $0,05(\mathrm{~F}<\alpha)$ yang berarti variabel bebas yaitu servant leadership $\left(\mathrm{X}_{1}\right)$ dan komitmen organisasional $\left(\mathrm{X}_{2}\right)$ berpengaruh signifikan secara bersama-sama terhadap variabel terikat yaitu kinerja karyawan (Y), sehingga penelitian ini dinyatakan layak digunakan sebagai model regresi.

Tabel 8.

Hasil Uji F

\begin{tabular}{llrrrrr}
\hline Model & & Sum of Squares & Df & Mean Square & \multicolumn{1}{c}{ F } & Sig. \\
\hline 1 & Regression & 2528.973 & 2 & 1264.487 & 119.881 & $.000^{\mathrm{b}}$ \\
& Residual & 495.747 & 47 & 10.548 & & \\
& Total & 3024.720 & 49 & & & \\
\hline
\end{tabular}

Sumber: Data diolah, 2018

Berdasarkan hasil analisis regresi linear berganda Tabel 5, diketahui bahwa variabel servant leadership memiliki nilai koefisien $\beta$ sebesar 0,342 dengan nilai signifikansi 0,004 yang lebih kecil dari 0,05 . Nilai koefisien $\beta<0$ dan nilai 
signifikansi $0,000<0,05$ mengindikasikan bahwa servant leadership berpengaruh positif dan signifikan terhadap kinerja karyawan. Dengan demikian $\mathrm{H}_{\mathrm{a}}$ diterima.

Berdasarkan hasil analisis regresi linear berganda Tabel 5, diketahui bahwa variabel komitmen organisasional memiliki nilai koefisien $\beta$ sebesar 0,651 dengan nilai signifikansi 0,001 yang lebih kecil dari 0,05 . Nilai koefisien $\beta<0$ dan nilai signifikansi $0,000<0,05$ mengindikasikan bahwa komitmen organisasional berpengaruh positif dan signifikan terhadap kinerja karyawan. Dengan demikian $\mathrm{H}_{\mathrm{a}}$ diterima.

Berdasarkan Uji F yang dihasilkan ini sejalan dengan penelitian dari Olesia et al. (2013) yang menyatakan bahwa pemimpin yang memahami tradisi, budaya dan keinginan karyawan, cenderung mampu meningkatkan komitmen organisasi karyawannya sehingga pada gilirannya mampu meningkatkan kinerja perusahaan secara keseluruhan.

Pengujian dengan melihat nilai koefisien determinasi R-Square $\left(\mathrm{R}^{2}\right)$ adalah untuk mengetahui seberapa besar pengaruh perubahan variabel independen terhadap perubahan variabel dependen. Untuk melihat hasil analisis uji hipotesis koefisien determinasi $\left(\mathrm{R}^{2}\right)$ dapat dilihat melalui tabel model summary output SPSS pada kolom R Square sebagai berikut:

Tabel 9.

Uji Koefisien Determinasi $\left(\mathbf{R}^{2}\right)$

\begin{tabular}{|c|c|c|c|c|c|}
\hline \multirow[b]{2}{*}{ Model } & \multicolumn{4}{|c|}{ Model Summary $^{\mathrm{b}}$} & \multirow[b]{2}{*}{ Durbin-Watson } \\
\hline & $\mathbf{R}$ & R Square & $\begin{array}{l}\text { Adjusted R } \\
\text { Square }\end{array}$ & $\begin{array}{c}\text { Std. Error of the } \\
\text { Estimate }\end{array}$ & \\
\hline 1 & $.914^{\mathrm{a}}$ & .836 & .829 & 3.248 & 1.229 \\
\hline
\end{tabular}

Berdasarkan hasil analisis data pada tabel 9 di atas diperoleh nilai koefisien determinasi $\left(\mathrm{R}^{2}\right)$ adalah sebesar 0,836 atau 83,6 persen kinerja karyawan Bank Sultra Kendari dipengaruhi oleh servant leadership dan komitmen organisasional, sedangkan sisanya sebesar 16,4 persen dipengaruhi oleh variabel lain.

Model yang terbentuk menjelaskan hubungan antara variabel servant leadership dan komitmen organisasional terhadap kinerja karyawan di Bank Sultra Kendari.

$$
\begin{aligned}
& \text { Kınerja Karyawan }_{i} \\
& \qquad=0,645+0,342^{*} \text { Servant Leadership }+0,651^{*} \text { Komitmen Organisasi }_{i}
\end{aligned}
$$

Model di atas menjelaskan hubungan antara variabel servant leadership terhadap variabel kinerja karyawan di Bank Sultra Kendari. Berdasarkan koefisien servant leadership yang bernilai 0,342, maka setiap kenaikan satu persen akan meningkatkan kinerja karyawan apabila variabel lain dianggap konstan. Hasil ini memberikan makna bahwa servant leadership mempunyai pengaruh yang signifikan terhadap kinerja karyawan di Bank Sultra bagian Dana. Sementara nilai sig t sebesar 0,004 menunjukkan bahwa semakin baik gaya servant leadership, maka ada kecenderungan kinerja karyawan akan meningkat. Dengan demikian dapat disimpulkan bahwa gaya kepemimpinan servant leadership berpengaruh signifikan dan positif terhadap kinerja karyawan di Bank 
Sultra Kendari, dapat diartikan juga bahwa penelitian ini mendukung adanya Path Goal Theory bahwa presepsi karyawan tentang harapan antara usaha dan kinerja sangat dipengaruhi oleh perilaku seorang pemimpin yang dapat dibuktikan dari hasil penelitian yang serupa dengan (Indartono et al., 2010), (Sial et al., 2014) (Harianto et al., 2014), Purwandari (2016), Muhammad Aji (2016) mengatakan bahwa servant leardeship berpengaruh positif dan signifikan terhadap kinerja karyawan.

Hasil penelitian ini sejalan dengan analisis deskriptif yang ditunjukkan oleh tanggapan karyawan terhadap variabel servant leadership, yaitu yang menunjukkan tingkat persepsi responden terhadap variabel servant leadership dengan nilai rata-rata untuk variabel servant leadership sebesar 3,78 dan nilai rata-rata variabel kinerja karyawan adalah sebesar 3,83 atau dalam kategori baik. Artinya bahwa kondisi kepemimpinan yang dirasakan karyawan adalah baik dapat menghasilkan kinerja karyawan yang baik.

Model yang terbentuk menjelaskan hubungan antara variabel komitmen organisasional terhadap kinerja karyawan di Bank Sultra Kendari.

$$
\begin{aligned}
& \text { Kinerja Karyawan }_{i} \\
& \qquad=0,645+0,342^{*} \text { Servant Leadership }+0,651^{*}{\text { Komitmen Organisas } i_{i}}
\end{aligned}
$$

Model di atas menjelaskan hubungan antara variabel komitmen organisasional terhadap variabel kinerja karyawan di Bank Sultra. Berdasarkan koefisien komitmen organisasional yang bernilai 0,651 , maka setiap kenaikan satu persen akan meningkatkan kinerja karyawan apabila variabel lain dianggap konstan. Hasil ini memberikan makna bahwa komitmen organisasional mempunyai pengaruh yang signifikan terhadap kinerja karyawan di Bank Sultra bagian Dana. Sementara nilai sig t sebesar 0,001 menunjukkan bahwa semakin tinggi komitmen organisasional pada diri karyawan maka cenderung kinerja karyawan akan meningkat. Dengan demikian dapat disimpulkan bahwa komitmen organisasional berpengaruh signifikan dan positif terhadap kinerja karyawan di Bank Sultra Kendari. Hasil penelitian ini juga mendukung adanya Teori Pertukaran Sosial (SET) bahwa karyawan diperlakukan dengan baik oleh perusahaan sehingga karyawan memiliki komitmen untuk memberikan balasan dengan perilaku positif melalui kinerja karyawan.

Hasil penelitian ini sejalan dengan analisis deskriptif yang ditunjukkan oleh tanggapan karyawan terhadap variabel komitmen organisasional menunjukkan nilai rata-rata untuk variabel komitmen organisasional sebesar 3,73 dan nilai ratarata skor variabel kinerja karyawan sebesar 3,87 atau dalam kategori baik. Hal tersebut memberikan interprestasi bahwa jika komitmen organisasional karyawan baik maka kinerja karyawan juga akan baik. Hasil penelitian ini serupa dengan temuan (Syauta et al., 2010), (Irefin \& Mechanic, 2014), (Arina, 2014), (Lotunani et al., 2014) Purwandari (2016) yang menyatakan bahwa komitmen organisasional berpengaruh positif dan signifikan terhadap kinerja pegawai.

Hasil penelitian ini menunjukkan bahwa servant leadership berpengaruh signifikan terhadap kinerja karyawan. Hal tersebut menunjukkan bahwa secara umum karyawan menganggap perilaku atasan dalam menerapkan tugas mencerminkan kepemimpinan servant leadership. Skor rata-rata indikator servant 
leadership yang memiliki skor terendah adalah kemampuan atasan mengontrol emosi, kemampuan atasan menjadi contoh dalam meningkatkan prestasi kerja, kemampuan atasan menunjukkan kerendahan hatinya serta kemampuan atasan menerima ide dari bawahannnya. Hal ini mengandung implikasi agar manajemen dalam pengambilan keputusan promosi gunakan variabel emotional intelligence sebagai kriteria promosi manajer baru dan memberikan pelatihan kepada para manajer yang ada khususnya pada bidang Dana. Dalam keputusan promosi untuk jabatan manajer disarankan agar mempertimbangkan level hasrat berprestasi individu.

Selanjutnya, Hasil penelitian ini menunjukkan bahwa komitmen organisasional berpengaruh signifikan terhadap kinerja karyawan. Hal tersebut menunjukkan bahwa secara umum karyawan memiliki komitmen organisasional yang cukup tinggi. Komitmen organiasasional yang memiliki skor terendah adalah bahwa individu tidak memiliki alasan kuat untuk meninggalkan organisasi, individu tidak ingin meninggalkan organisasi, individu senang menceritakan lingkungan kerja pada orang lain, individu akan menolak organisasi lain meskipun ditawari gaji/jabatan lebih tinggi. Hal tersebut mengandung implikasi bahwa manajemen harus memastikan bahwa individu karyawan yang bekerja pada Bank Sultra Kendari mampu meningkatkan pengumpulan dana pihak ketiga, melaksanakan interaksi yang berkualitas untuk memelihara hubungan baik dengan pelanggan dan cepat serta tanggap dalam menangani keluhan nasabah Bank Sultra Kendari dengan demikian loyalitas karyawan yang tinggi memberikan manfaat finansial yang positif.

Adapun keterbatasan dalam penelitian ini yaitu jumlah responden hanya 50 karyawan dan hanya dari bagian Dana, sehingga hasil penelitian ini hanya dapat diterapkan di lingkungan kerja bagian Dana Bank Sutra Kendari dan tidak dapat digeneralisir pada divisi lain dan lingkungan perusahaan lain. Penelitian ini tidak mencantumkan faktor lain kedalam model dari sisa determinasi total sebesar 16,4 persen. Mengingat penelitian ini dilakukan dalam jangka waktu yang cukup singkat menyebabkan penelitian ini penting untuk dilakukan kembali dengan variabel yang berbeda.

\section{SIMPULAN}

Berdasarkan hasil analisis data serta pembahasan mengenai pengaruh masing-masing variabel yang telah dipaparkan, maka dapat ditarik kesimpulan sebagai berikut:

Servant Leadership berpengaruh positif dan signifikan terhadap kinerja karyawan di Bank Sultra Kendari. Hasil tersebut membuktikan bahwa semakin baik gaya servant leadership, maka ada kecenderungan kinerja karyawan akan meningkat.

Komitmen organisasional berpengaruh positif dan signifikan terhadap kinerja karyawan di Bank Sultra Kendari. Hasil tersebut membuktikan bahwa semakin tinggi komitmen organisasional pada diri karyawan, maka ada kecenderungan kinerja karyawan akan meningkat. 
Saran bagi manajemen Bank Sultra Kendari yaitu agar manajemen dalam pengambilan keputusan promosi gunakan variabel emotional intelligence sebagai kriteria promosi manajer baru dan memberikan pelatihan kepada para manajer yang ada khususnya pada bidang Dana. Dalam keputusan promosi untuk jabatan manajer disarankan agar mempertimbangkan level hasrat berprestasi individu serta manajemen harus memastikan bahwa individu karyawan yang bekerja pada Bank Sultra Kendari mampu meningkatkan pengumpulan dana pihak ketiga, melaksanakan interaksi yang berkualitas untuk memelihara hubungan baik dengan pelanggan dan cepat serta tanggap dalam menangani keluhan nasabah Bank Sultra Kendari dengan demikian loyalitas karyawan yang tinggi memberikan manfaat finansial yang positif.

Penelitian ini hanya sebatas meneliti mengenai servant leadership dan komitmen organisasional terhadap kinerja karyawan. Peneliti selanjutnya diharapkan untuk menambah variabel lain seperti variabel kepuasaan kerja, motivasi kerja, budaya organisasi untuk mengetahui kinerja karyawan serta menambah variabel kondisional sebagai variabel moderasi. Peneliti selanjutnya juga diharapkan untuk dapat mengambil sampel di beberapa divisi lainnya yang ada di Bank Sultra Kendari.

\section{REFERENSI}

Adi, I. K., Atmaja, W., Ayu, I. G., \& Adnyani, D. 2016. Organizational Citizenship Behavior Fakultas Ekonomi dan Bisnis Universitas Udayana, Bali. 5(11), pp 7245-7271.

Allen, N. J., \& Meyer, J. P. 1990. The measurement and antecedents of affective, continuance and normative commitment to the organization. Journal of Occupational Psychology.

Arina, N. 2014. ORGANISASI TERHADAP KINERJA KARYAWAN ( Studi pada Pegawai Perum Perumnas Jakarta ).

Dramawan. 2017. Pengaruh Kepemimpinan Transformasional dan Komitmen Organisasional Terhadap Organizational Citizenship Behavior di Kantor Inspektorat Kabupaten Badung. 6(12), pp 6880-6912.

Fauzan, A. H., \& Sumiyati. 2014. Pengaruh Komitmen Organisasi terhadap Kinerja Karyawan PT. Bank Mandiri. Tbk. Area Cirebon (Yos Sudarso), 120.

Hair, J. F., Anderson, R. E., Tatham, R. L., \& Black, W. C. 1998. Multivariate data analysis with readings (5nd ed.). Prentice-Hall, Upper Saddle River.

Harianto, T. L., Shaleh, C., Ekonomi, F., Unej, U. J., \& Kalimantan, J. 2014. Pengaruh Servant Leadership Terhadap Kinerja Pegawai Melalui Disiplin Kerja Pada Dinas Pekerjaan Umum (PU) Pengairan Kabupaten Banyuwangi. 
Artikel Ilmiah Mahasiswa.

Indartono, S., Chiou, H., \& Chen, C.-H. V. 2010. The joint moderating impact of personal job fit and servant leadership on the relationship between the task characteristics of job design and performance. Interdisciplinary Journal of Contemporary Research in Business. 2(8), pp 42-61.

Irefin, P., \& Mechanic, M. A. 2014. Effect of Employee Commitment on Organizational Performance in Coca Cola Nigeria Limited Maiduguri, Borno State. IOSR Journal of Humanities and Social Science. 19(3), pp 33-41.

Kamanjaya, I. G. H., \& Supartha, W. G. 2017. Pengaruh Servant Leadership Terhadap Komitmen Organisasional Dan Kinerja Pegawai (Studi pada Pegawai Negeri Sipil di RSUD Wangaya Kota Denpasar ) Fakultas Ekonomi dan Bisnis Universitas Udayana, Bali. E-Jurnal Ekonomi Dan Bisnis Universitas Udayana. 6(7), pp 2731-2760.

Kaplan, Robert S; Norton, D. P. 1992. The Balanced Scorecard - Measures That Drive Performance. Harvard Business Review TA -.70(1), pp 71.

Liden, R. C., Wayne, S. J., Liao, C., \& Meuser, J. D. 2014. Servant Leadership \& Serving Culture. Academy of Management Journal. 57(5), pp 1434-1452.

Lotunani, A., Afnan, E., \& Setiawan, M. 2014. The Effect of Competence on Commitment, Performance and Satisfaction with Reward as a Moderating Variable (A Study on Designing Work plans in Kendari City Government, Southeast Sulawesi). International Journal of Business and Management Invention ISSN, 3(2), pp 18-25.

Mathis, R. L., \& Jackson, J. H. 2001. Manajemen Sumber Daya Manusia, terjemahan Jimmy Sadeli dan Bayu Prawira Hie. Jakarta: Salemba Empat (PT. Salemba Emban Patria).

Mazarei, E., Hoshyar, M., Nourbakhsh, P., \& Instructor, E. P. 2013. The Relationships between Servant Leadership Style and Organizational Commitment. Physical Education Instructor, Bushehr, Iran Ph . D , College of Physical Education, Islamic Azad University, 5(1), pp 312-317.

Mowday, R. T., Steers, R. M., \& Porter, L. W. 1982. Employee-Organization Linkages: The Psychology of Commitment, Absenteeism, and Turnover. New York Academic Press.

Muhammad Aji dan Palupiningdyah. 2016. Pengaruh Servant Leadership terhadap Kinerja Karyawan dengan Burnout sebagai Variabel Intervening. Management Analysis Journal.. Jurusan Manajemen Fakultas Ekonomi Universitas Negeri Semarang. 5 (3) pp 178-88.

Murty, aprilia, windy, dan hudiwinarsih, G. 2012. Pengaruh Kompensasi, 
Motivasi dan Komitmen Organisasional Terhadap Kinerja Karyawan Bagian Akuntansi. 2(2), pp 215-228.

Olesia, W. S., Namusonge, G. S. S., \& Iravo, M. E. 2013. Role of Servant Leadership on Organizational Commitment: An Exploratory Survey of State Corporations in Kenya. International Journal of Humanities and Social Science.

Purwandari. 2016. Pengaruh servant leadership dan komitmen organisasi terhadap kinerja karyawan (studi pada Child Development Sponsor Program Compassion Indonesia Cluster DIY). Sumber :eprints.uny.ac.id/43256/1/LiaAnggraenyPurwandari_10408141047.pdf.Di akses tanggal 21 desember 2018.

Sen, S., \& Sarros, J. C. 2002. Servant leadership: It's origin, development, and application in organizations. Journal of Leadership \& Organizational Studies (Baker College).

Sial, A., Wqaas, S., Kousar, A., \& Habib, S. 2014. Impact of servant leadership on knowledge sharing intentions. European Journal of Business and Innovation Resarch. 2(1), pp 1-11.

Spears, L. C. 2010. Character and Servant Leadership: Ten Characteristics of Effective, Caring Leaders. Concept and Connections.

Suryadharma, I. M. A., Riana, I. G., \& Sintaasih, D. K. 2016. Kepuasan Kerja Dan Kinerja Karyawan ( Studi Pada Pt . Bpr Sri Artha Lestari Denpasar ) Fakultas Ekonomi Dan Bisnis Universitas Udayana ( Unud ), Bali. E-Jurnal Ekonomi Dan Bisnis Universitas Udayana. 2, pp 335-358.

Syauta, J. H., Troena, E. A., Setiawan, M., \& Solimun. 2010. The Influence of Organizational Culture, Organizational Commitment to Job Satisfaction and Employee Performance (Study at Municipal Waterworks of Jayapura, Papua Indonesia). International Journal of Business and Management Invention, l(1), pp 69-76.

Trompenaars, F., \& Voerman, E. 2010. Harnessing the Strength of the World's Most Powerful Management Philosophy. Servant Leadership Across Cultures. Journal of Chemical Information and Modeling.

Van Dierendonck, D., \& Nuijten, I. 2011. The Servant Leadership Survey: Development and Validation of a Multidimensional Measure. Journal of Business and Psychology, 26(3), 249-267.

Vondey, M. (2008). The Relationships among Servant Leadership, Organizational Citizenship Behavior, Person-Organization Fit, and Organizational Identification. International Journal. 
E-Jurnal Manajemen, Vol. 8, No. 10, 2019 : 5984-6001

Walumbwa, F. O., Hartnell, C. A., \& Oke, A. (2010). Servant Leadership, Procedural Justice Climate, Service Climate, Employee Attitudes, and Organizational Citizenship Behavior: A Cross-Level Investigation. Journal of Applied Psychology.

Wirawan. (2009). Kinerja. In EVALUASI KINERJA SUMBER DAYA MANUSIA. 